\title{
Genome Mining, Heterologous Expression, Antibacterial and Antioxidant Activities of Lipoamides and Amicoumacins from Compost-Associated Bacillus subtilis fmb60
}

\author{
Jie Yang ${ }^{1,2,3}$, Qingzheng Zhu ${ }^{1}$, Feng Xu ${ }^{1}$, Ming Yang ${ }^{4}$, Hechao Du ${ }^{5}$, Xiaoying Bian ${ }^{4}{ }^{\oplus}$, Zhaoxin Lu ${ }^{5}$, \\ Yingjian $\mathrm{Lu}^{6, *}$ and Fengxia $\mathrm{Lu}^{5, *}$
}

Citation: Yang, J.; Zhu, Q.; Xu, F.; Yang, M.; Du, H.; Bian, X.; Lu, Z.; Lu, Y.; Lu, F. Genome Mining, Heterologous Expression, Antibacterial and Antioxidant Activities of Lipoamides and Amicoumacins from Compost-Associated Bacillus subtilis fmb60. Molecules 2021, 26, 1892. https://doi.org/

10.3390/molecules26071892

Academic Editor: Daniel Krug

Received: 2 March 2021

Accepted: 23 March 2021

Published: 26 March 2021

Publisher's Note: MDPI stays neutral with regard to jurisdictional claims in published maps and institutional affiliations.

Copyright: (c) 2021 by the authors. Licensee MDPI, Basel, Switzerland. This article is an open access article distributed under the terms and conditions of the Creative Commons Attribution (CC BY) license (https:/ / creativecommons.org/licenses/by/ $4.0 /)$.
1 Jiangsu Key Laboratory of Marine Bioresources and Environment, Jiangsu Ocean University, Lianyungang 222005, China; yangjie0737@163.com (J.Y.); zhuqingzheng2020@163.com (Q.Z.); xufeng0737@163.com (F.X.)

2 Co-Innovation Center of Jiangsu Marine Bio-industry Technology, Jiangsu Ocean University, Lianyungang 222005, China

3 Jiangsu Marine Resources Development Research Institute, Lianyungang 222000, China

4 Helmholtz Institute of Biotechnology, State Key Laboratory of Microbial Technology, Shandong University, Qingdao 266237, China; yangming_232514@163.com (M.Y.); bianxiaoying@sdu.edu.cn (X.B.)

5 College of Food Science and Technology, Nanjing Agricultural University, 1 Weigang, Nanjing 210095, China; duhechao1990@163.com (H.D.); fmb@njau.edu.cn (Z.L.)

6 College of Food Science and Engineering, Nanjing University of Finance and Economics, Nanjing 210003, China

* Correspondence: yingjianlu@nufe.edu.cn (Y.L.); lufengxia@njau.edu.cn (F.L.); Tel./Fax: +86-258-439-5155 (Y.L.); +86-258-439-5963 (F.L.)

Abstract: Bacillus subtilis fmb60, which has broad-spectrum antimicrobial activities, was isolated from plant straw compost. A hybrid NRPS/PKS cluster was screened from the genome. Sixteen secondary metabolites produced by the gene cluster were isolated and identified using LC-HRMS and NMR. Three lipoamides D-F (1-3) and two amicoumacin derivatives, amicoumacins D, E $(4,5)$, were identified, and are reported here for the first time. Lipoamides D-F exhibited strong antibacterial activities against harmful foodborne bacteria, with the MIC ranging from 6.25 to $25 \mu \mathrm{g} / \mathrm{mL}$. Amicoumacin E scavenged $38.8 \%$ of $\mathrm{ABTS}^{+}$radicals at $1 \mathrm{mg} / \mathrm{mL}$. Direct cloning and heterologous expression of the NRPS/PKS and ace gene cluster identified its importance for the biosynthesis of amicoumacins. This study demonstrated that there is a high potential for biocontrol utilization of B. subtilis fmb60, and genome mining for clusters of secondary metabolites of B. subtilis $\mathrm{fmb60}$ has revealed a greater biosynthetic potential for the production of novel natural products than previously anticipated.

Keywords: Bacillus subtilis; NRPS/PKS; amicoumacins; heterologous expression; bioactivities

\section{Introduction}

Bacillus subtilis is nonpathogenic, and displays considerable genetic diversity, even among closely related strains. Its secondary metabolites have been studied for more than 50 years, and numerous studies have revealed that the secondary metabolites are characterized by antimicrobial and other biological activities. [1] B. subtilis has been widely used in the food industry and agriculture for inhibiting and eliminating foodborne and plant pathogens [2,3]. Genomic sequencing revealed that an average of $4-5 \%$ of the genome in each strain is devoted to the synthesis of bioactive compounds, giving the organism the potential to produce more than two dozen antibiotics with a great variety of structures [4].

Improvements in sequencing technology have made genome mining an important tool for the discovery of novel natural products $[5,6]$. During the last decade, the rapid development of bioinformatics tools, as well as improved sequencing and annotation of microbial genomes, has led to the discovery of novel bioactive compounds synthesized 
by non-ribosomal peptide synthetases (NRPS), polyketide synthases (PKS), and hybrid NRPS/PKS, known as biosynthesis gene clusters (BGCs). This method for the identification of novel substances currently plays an important role in the food industry and in agriculture [7-9]. PKS and NRPS synthetic products represent one of the largest classes of microbial natural products, and have important clinical and ecological impacts [10]. PKS and NRPS synthetic products present striking similarities in their biosynthetic assembly mechanisms. The presence of gene clusters allows the existence of hybrid clusters that contain elements of each class, resulting in the formation of hybrid NRPS/PKS [11]. These hybrid NRPS/PKS clusters provide even greater potential for numerous varieties of secondary metabolites to be generated by microorganisms $[12,13]$.

The transfer of BGCs from the original host into a feasible heterologous host, resulting in heterologous expression, has become a valid alternative approach for identifying the gene clusters required for the biosynthesis of compounds. In 2012, we described a method termed linear plus linear homologous recombination (LLHR) to directly clone large BGCs from digested genomic DNA in Escherichia coli. LLHR is mediated by the prophage recombinase RecET in E. coli [14]. In 2016, an improved method, exonuclease combined with RecET recombination, was described [15].

In the present study, wild-type B. subtilis fmb60 isolated from compost was shown to exhibit a broad spectrum of antimicrobial activities. The genome sequence of $B$. subtilis fmb60 was investigated, and potential secondary metabolite clusters were predicted using antiSMASH. The genome contained three NRPS clusters, one type I PKS cluster, and one NRPS/PKS cluster. Several products of the NRPS cluster metabolites have already been confirmed, including surfactin, fengycin, and bacillibactin. The type I PKS cluster metabolites have also been identified in our previous studies, involving aurantinins B, C, and D [16]. However, the secondary metabolites synthesized by the hybrid NRPS/PKS cluster of $B$. subtilis fmb60 have not been well studied. In this study, based on the analysis of hybrid NRPS/PKS clusters, three new lipoamides D-F (1-3), two new amicoumacins D, $\mathrm{E}(\mathbf{4}, \mathbf{5})$, and 11 known amicoumacins metabolites $(\mathbf{6}-\mathbf{1 6})$ were identified in this study. The antimicrobial activity of 1-16 was evaluated. Compounds 1-3, 7, and $\mathbf{1 1}$ showed significant antibacterial activity. The antioxidant activity of 6-16 was evaluated. Compounds 5, 6, 13, 15, and 16 showed significant FRAP activities and $\mathrm{ABTS}^{+}$radical scavenging activities. The ExoCET method was used to directly clone and synthesize related gene clusters and perform metabolite analysis on B. subtilis fmb60.

\section{Results}

\subsection{Genome Sequencing, Annotation, and Bioinformatics Analysis}

The genome of B. subtilis fmb60 was sequenced, and three scaffolds were acquired. The draft genome sequences were deposited in GenBank under accession number LYMC01000002.1. Using the gene prediction software Glimmer, 3045 genes were predicted, of which 2829 genes were identified as having homologues. These homologous proteins were derived from 80 species, including Bacillus sp. JS, B. subtilis subsp. subtilis str. 168, and B. subtilis QB928. Bacillus $\mathrm{sp}$. JS contained the greatest number of homologous proteins, accounting for $63.6 \%$ [17].

Analysis of the B. subtilis fmb60 genome using antiSMASH 5.2.0 revealed 17 possible secondary metabolite biosynthetic gene clusters, of which three NRPS clusters, two PKS clusters, and one hybrid NRPS/PKS cluster had the capacity to produce bioactive metabolites. Focusing on the gene cluster of the hybrid NRPS/PKS, it was found that this gene cluster was homologous with the genome of B. subtilis subsp. inaquosorum KCTC $13,429(91 \%)$ and the biosynthetic genes of xenocoumcin (28\%). Xenocoumacin includes $X_{c n} 1$ and $X_{c n} 2$, which are amicoumacin derivatives with amino acid and carboxylic acid hybrid moieties. These derivatives are the major antimicrobial compounds isolated from Xenorhabdus nematophila [18]. Further studies showed that a hybrid NRPS/PKS gene cluster $(x \subset n A-N)$ was required for their synthesis [19]. The $x c n A$ and $x c n G$ genes are responsible for synthesizing an important precursor ( $N$-acyl-D-Asn), and cleaving prexenocoumacins in the production of xenocoumacin in the biosynthesis gene cluster of xenocoumacin. 
Thus, the hybrid NRPS/PKS cluster from B. subtilis fmb60 was predicted to synthesize amicoumacins.

\subsection{Isolation and Characterization of Lipoamides}

In searching for possible lipoamides, it was noticed that apart from fengycin, surfactin, and bacillibactin, another fraction of the crude extracts was eluted from the semipreparation HPLC. Three novel compounds were isolated from this fraction.

The structure of compound 1 was determined using ${ }^{1} \mathrm{H}$ and ${ }^{13} \mathrm{CNMR}$ spectroscopy and heteronuclear single quantum coherence spectroscopy (HSQC) data. The ${ }^{13} \mathrm{C}$ NMR and DEPT spectra displayed 35 carbon signals, classified as three carbonyls, two methyl, 10 methylene, and two methylidynes (Table 1). The planar structure of compound 1 was established using two-dimensional (2D) NMR data (Figure 1A). In the HSQC, ${ }^{1} \mathrm{H}-{ }^{1} \mathrm{H}$ COSY, and heteronuclear multiple bond correlation (HMBC) spectra of compound $\mathbf{1}, \mathrm{C}-2^{\prime}$ $\left(\delta_{\mathrm{C}} 50.5, \delta_{\mathrm{H}} 4.70, \mathrm{t}\right)$ was easily recognized and set as a starting point. The key HMBC correlations of $\mathrm{H}-2^{\prime}\left(\delta_{\mathrm{H}} 4.70, \mathrm{t}\right)$ to $\mathrm{C}-1^{\prime}\left(\delta_{\mathrm{C}} 175.1\right), \mathrm{C}-3^{\prime}\left(\delta_{\mathrm{C}} 37.9\right), \mathrm{C}-4^{\prime}\left(\delta_{\mathrm{C}} 174.1\right)$, and $\mathrm{C}-1\left(\delta_{\mathrm{C}}\right.$ 176.2), as well as $\mathrm{H}-3^{\prime}\left(\delta_{\mathrm{H}} 2.75,1.31, \mathrm{~m}\right)$ to $\mathrm{C}-1^{\prime}\left(\delta_{\mathrm{C}} 175.1\right)$ and $\mathrm{C}-4^{\prime}\left(\delta_{\mathrm{C}} 174.1\right)$ indicated the existence of an Asn unit. Two methyl proton signals at $\delta_{\mathrm{H}} 0.85$ and a broad peak at $\delta_{\mathrm{H}} 1.31$ indicated the presence of an iso fatty acid side chain, a finding which was supported by the correlation spectroscopy (COSY, HSQC, and DEPT) data. Two ${ }^{1} \mathrm{H}-{ }^{1} \mathrm{H}$ COSY spin subunits were recognized. These two subunits are linked through an amide bond, as evidenced by the HMBC correlation from $\mathrm{H}-2^{\prime}\left(\delta_{\mathrm{H}} 4.70, \mathrm{t}\right)$ to $\mathrm{C}-1\left(\delta_{\mathrm{C}} 176.2\right)$. Further comprehensive analysis of 2D NMR data showed that the branched-chain methyl fatty acid of compound $\mathbf{1}$ is different from that of lipoamide A and other similar structures [20,21]. The position of the methyl group at $C-13$, which was manifested by the HMBC correlations of C-13 (19.7) to $\mathrm{H}-11\left(\delta_{\mathrm{H}} 1.31,1.09\right)$, and $\mathrm{C}-12\left(\delta_{\mathrm{C}} 11.8\right)$ was correlated with $\mathrm{H}-11\left(\delta_{\mathrm{H}} 1.31,1.09\right)$. Thus, the structure of compound 2 was proposed, as shown in Figure 1B, and named lipoamide D.

Table 1. ${ }^{1} \mathrm{H}$ NMR ( in Hz), ${ }^{13} \mathrm{C}$ NMR spectral data of lipomide D-F, 1-3, in methanol- $d_{4}$.

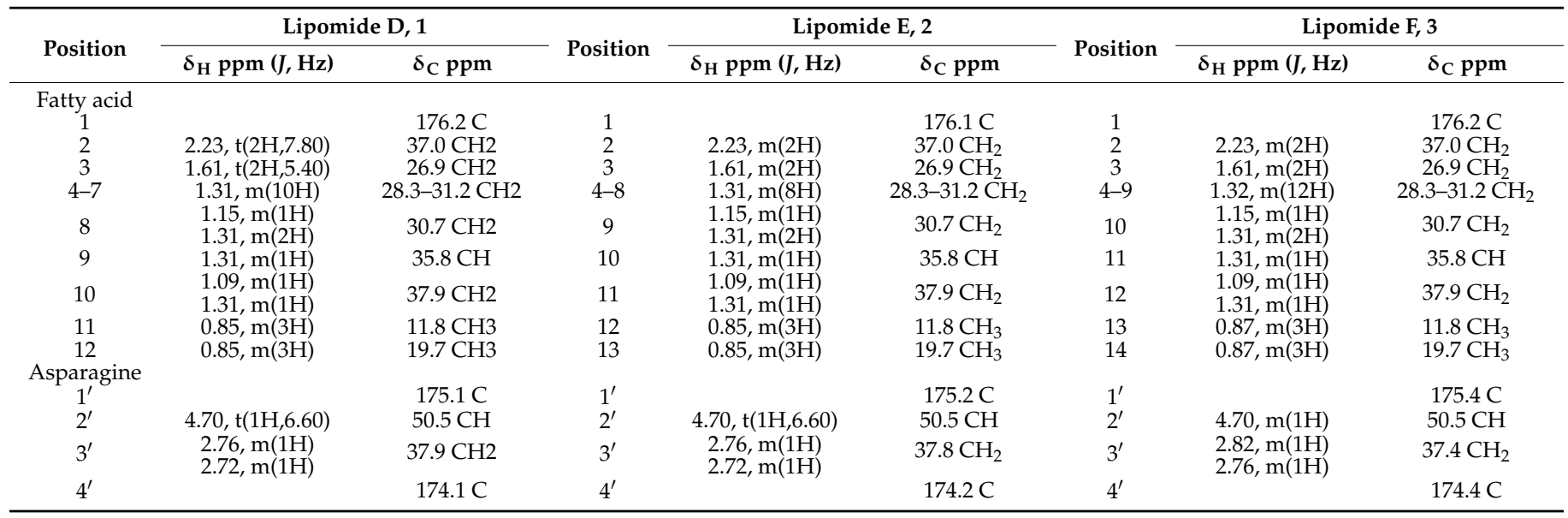

The structure of compound 2 was investigated using NMR spectroscopy. These data revealed that compound 2 possessed structural similarities to compound $\mathbf{1}$, but differed from the molecular formula of compound 1 by the addition of $-\mathrm{CH}_{2}\left(\delta_{\mathrm{C}} 30.4, \delta_{\mathrm{H}} 1.31\right)$ (Table 1). By analyzing the HSQC and HMBC, the position of the methyl group was confirmed at C-12. Thus, compound 2's structure was proposed, as shown in Figure 1B, and it is first named lipoamide $\mathrm{E}$. 
A

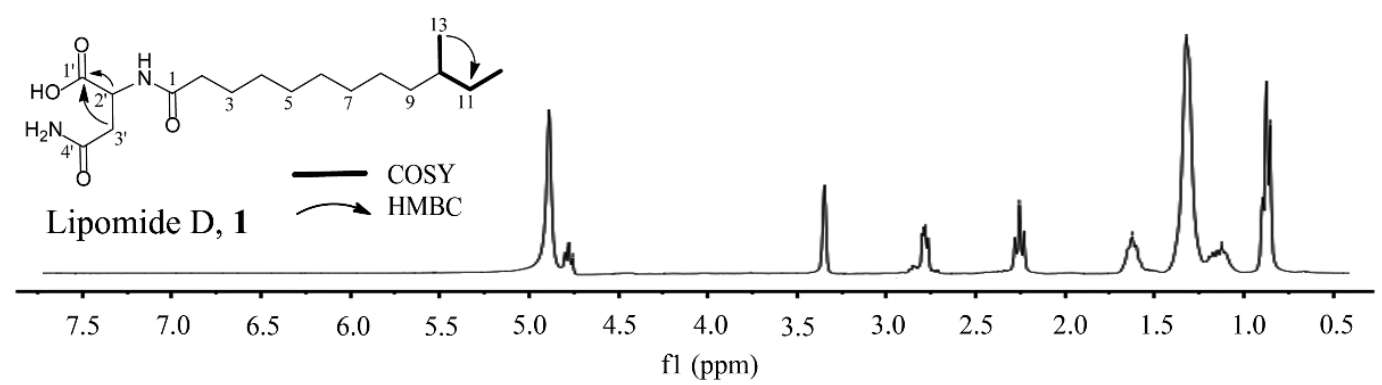

B<smiles>CCC(C)CCCCCCCCC(=O)NC(CC(N)=O)C(=O)O</smiles>

Lipoamide E, $2 \mathrm{n}=1$

Lipoamide $\mathrm{F}, 3 \mathrm{n}=3$

Figure 1. (A) ${ }^{1} \mathrm{H}$ NMR analysis, key ${ }^{1} \mathrm{H}-{ }^{1} \mathrm{H}$ COSY, $\mathrm{HMBC}$ correlations, and (B) structure of lipomide D-F, 1-3.

The structure of compound 3 was investigated using NMR spectroscopy. The 1D NMR spectra of compound $\mathbf{3}$ exhibited high similarities to those of compound $\mathbf{1}$, indicating that its structure was closely related to that of compound $\mathbf{1}$ (Table 1). The only difference was that the molecular weight of compound $\mathbf{3}$ was higher than $14 \mathrm{amu}$ of compound $\mathbf{1}$, while an additional carbon resonance signal $\left(\delta_{C} 30.3\right)$ could be observed. Meanwhile, the position of the methyl group was confirmed at $\mathrm{C}-14$ according to HSQC and HMBC analysis. Thus, compound $\mathbf{3}^{\prime}$ s structure was proposed, as shown in Figure $1 \mathrm{~B}$, and it is named lipoamide $\mathrm{F}$ for the first time.

\subsection{Isolation and Characterization of New Amicoumacins}

The fermentation broth of strain B. subtilis fmb60 was extracted with ethyl acetate. Thirteen compounds were isolated using HPLC, all of which exhibited similar UV spectra, indicating that they were probably structurally related. Analysis of the ${ }^{1} \mathrm{H},{ }^{13} \mathrm{C} N M R$, and ESI-HRMS/MS spectra of this extract revealed that the structure of the bioactive fractions was almost identical to that of isocoumarin-type compounds [22].

Compound 4 was isolated as an amorphous solid. The ESI-MS/MS spectrum of the precursor ion $[\mathrm{M}+\mathrm{H}]^{+}$was dominated by common ion peaks at $\mathrm{m} / z 372.1,250.1,233.1$, and 215.1 (Figure 2A). The ${ }^{1} \mathrm{H}$ and ${ }^{13} \mathrm{C}$ NMR resonances (Table 2) as well as ${ }^{1} \mathrm{H}-{ }^{1} \mathrm{H}$ COSY and HSQC, suggested the presence of 21 carbons, including three carbonyl carbons, six aromatic carbons, four methylenes, a methine, two methyls, and five carbons bonded to nitrogen or oxygen. These data revealed that compound 4 possessed structural similarities to amicoumacin $\mathrm{C}$ but differed from the molecular formula of amicoumacin $\mathrm{C}$ by the addition of $-\mathrm{CH}_{2}$ [23]. This methylene group was identified by two proton signals observed at $\delta_{\mathrm{H}}$ 2.36, 2.23 in the ${ }^{1} \mathrm{H}$ NMR spectrum, an observation which was supported by the associated carbon resonating at $\delta_{\mathrm{C}} 31.1$ in the HSQC spectrum. The ${ }^{1} \mathrm{H}-{ }^{1} \mathrm{H}$ COSY correlations from $\mathrm{H}-11^{\prime}\left(\delta_{\mathrm{H}} 2.22, \mathrm{~m} ; 2.16, \mathrm{~m}\right)$ to $\mathrm{H}-10^{\prime}\left(\delta_{\mathrm{H}} 3.88, \mathrm{~m}\right)$ and $\mathrm{H}-12^{\prime}\left(\delta_{\mathrm{H}} 2.36, \mathrm{~m} ; 2.23, \mathrm{~m}\right)$ suggested that $C-11^{\prime}\left(\delta_{C} 22.7\right)$ was connected with $C-10^{\prime}\left(\delta_{C} 57.8\right)$ and $C-12^{\prime}\left(\delta_{C} 31.1\right)$. The assignment of the methylene group at $\mathrm{C}-12^{\prime}$ was confirmed by the $\mathrm{HMBC}$ correlation from $\mathrm{H}-11^{\prime}\left(\delta_{\mathrm{H}}\right.$ $2.22, \mathrm{~m} ; 2.16, \mathrm{~m})$ and $\mathrm{H}-12^{\prime}\left(\delta_{\mathrm{H}} 2.36,2.23\right)$ to carbonyl carbon $\mathrm{C}-13^{\prime}\left(\delta_{\mathrm{C}} 181.5\right)$. The HMBC correlation of $\mathrm{H}-10^{\prime}\left(\delta_{\mathrm{H}} 3.88, \mathrm{~m}\right)$ and $\mathrm{C}-13^{\prime}\left(\delta_{\mathrm{C}} 181.5\right)$ suggested the presence of an amide bond between $\mathrm{C}-10^{\prime}$ and $\mathrm{C}-12^{\prime}$ (Figure $2 \mathrm{C}$ ). The relative configuration of compound 4 was determined by NOESY correlations of $\mathrm{H}-3 / \mathrm{H}-4^{\prime}, \mathrm{H}-5^{\prime} / \mathrm{H}-8^{\prime}$, and $\mathrm{H}-8^{\prime} / \mathrm{H}-10^{\prime}$, and shares stereochemical configurations similar to those of amicoumacin $\mathrm{C}$. Thus, compound 4 was 
assigned as a new amicoumacin derivative from the spectroscopic data analysis, and was named amicoumacin D.
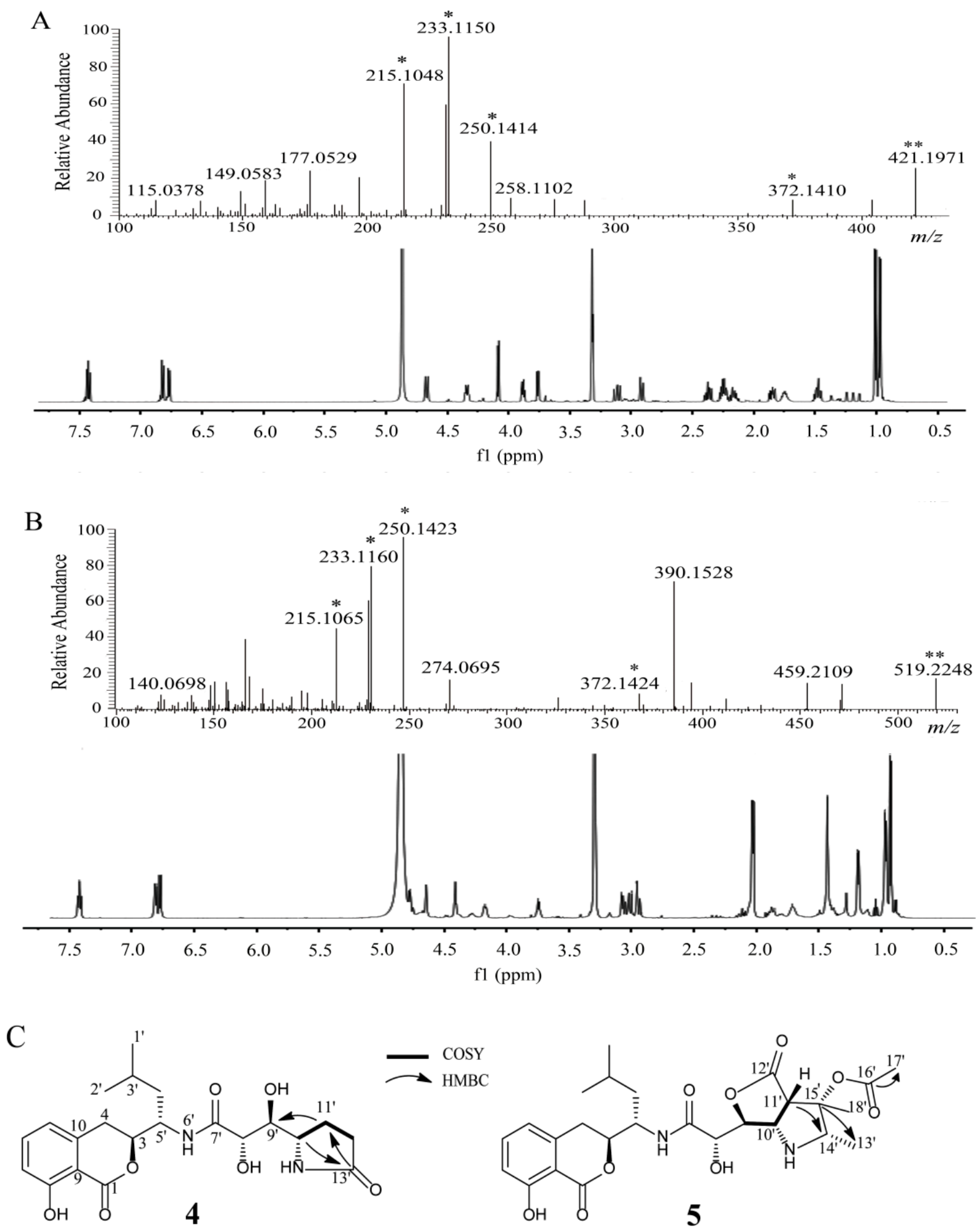

Figure 2. (A) HRMS/MS and ${ }^{1} \mathrm{H}$ NMR analysis of amicoumacin D, 4 (B) HRMS/MS and $(\mathbf{B})^{1} \mathrm{H}$ NMR analysis of amicoumacin E, 5. (C) Key ${ }^{1} \mathrm{H}-{ }^{1} \mathrm{H}$ COSY, HMBC, relative stereochemistry of amicoumacin D, 4, E, 5. * Characteristic ion peak. ** Precursor ion peak. 
Table 2. ${ }^{1} \mathrm{H}$ NMR $(J$ in $\mathrm{Hz}),{ }^{13} \mathrm{C}$ NMR spectral data of amicoumacin $\mathrm{D}, 4$, and E, 5, in methanol- $d_{4}$.

\begin{tabular}{|c|c|c|c|c|c|c|c|}
\hline \multirow{2}{*}{ Position } & \multicolumn{3}{|c|}{ Amicoumacin D, 4} & \multirow{2}{*}{ Position } & \multicolumn{3}{|c|}{ Amicoumacin E, 5} \\
\hline & $\delta_{\mathrm{H}} \operatorname{ppm}(J, \mathrm{~Hz})$ & $\delta_{C}$ ppm & НМВС & & $\delta_{\mathrm{H}} \operatorname{ppm}(J, \mathrm{~Hz})$ & $\delta_{\mathrm{C}} \mathrm{ppm}$ & НМВС \\
\hline 1 & & $171.1 \mathrm{C}$ & & 1 & & $171.3 \mathrm{C}$ & \\
\hline 3 & $4.66, \mathrm{dt}(1 \mathrm{H}, 12.5,3.0)$ & $82.8 \mathrm{CH}$ & $4,4^{\prime}$ & 3 & $4.80, \mathrm{~m}(1 \mathrm{H})$ & $82.1 \mathrm{CH}$ & 4 \\
\hline 4 & $\begin{array}{c}3.09, \mathrm{~m}(1 \mathrm{H}) \\
2.90, \mathrm{dd}(1 \mathrm{H}, 16.5,3.0)\end{array}$ & $30.9 \mathrm{CH}_{2}$ & 5 & 4 & $\begin{array}{c}3.04, \mathrm{~m}(1 \mathrm{H}) \\
2.95, \mathrm{dd}(1 \mathrm{H}, 13.5,2.5)\end{array}$ & $31.0 \mathrm{CH}_{2}$ & 5 \\
\hline 5 & 6.77, $\mathrm{d}(1 \mathrm{H}, 7.0)$ & $119.5 \mathrm{CH}$ & 4,7 & 5 & 6.80, d $(1 \mathrm{H}, 6.5)$ & $119.8 \mathrm{CH}$ & 4,7 \\
\hline 6 & $7.46, \mathrm{t}(1 \mathrm{H}, 8.0)$ & $137.5 \mathrm{CH}$ & & 6 & $7.45, \mathrm{t}(1 \mathrm{H}, 6.5)$ & $137.5 \mathrm{CH}$ & 5 \\
\hline 7 & $6.82, \mathrm{~d}(1 \mathrm{H}, 8.5)$ & $116.7 \mathrm{CH}$ & 5 & 7 & $6.83, \mathrm{~d}(1 \mathrm{H}, 7.0)$ & $116.7 \mathrm{CH}$ & 5 \\
\hline 8 & & 163.2 C & 6,7 & 8 & & $163.3 \mathrm{C}$ & 6,7 \\
\hline 9 & & $109.4 \mathrm{C}$ & $4,5,7$ & 9 & & $109.7 \mathrm{C}$ & $4,5,7$ \\
\hline 10 & & $141.6 \mathrm{C}$ & $3,4,5,6$ & 10 & & $141.7 \mathrm{C}$ & $4,5,6$ \\
\hline $1^{\prime}$ & $0.94, \mathrm{~d}(3 \mathrm{H}, 6.5)$ & $22.0 \mathrm{CH}_{3}$ & $2^{\prime}, 3^{\prime}, 4^{\prime}$ & $1^{\prime}$ & $0.93, \mathrm{~d}(3 \mathrm{H}, 5.5)$ & $21.8 \mathrm{CH}_{3}$ & $2^{\prime}, 3^{\prime}, 4^{\prime}$ \\
\hline $2^{\prime}$ & $0.98, \mathrm{~d}(3 \mathrm{H}, 6.5)$ & $23.7 \mathrm{CH}_{3}$ & $1^{\prime}, 3^{\prime}, 4^{\prime}$ & $2^{\prime}$ & $0.98, \mathrm{~d}(3 \mathrm{H}, 6.0)$ & $23.8 \mathrm{CH}_{3}$ & $1^{\prime}, 3^{\prime}, 4^{\prime}$ \\
\hline $3^{\prime}$ & $1.72, \mathrm{~m}(1 \mathrm{H})$ & $25.8 \mathrm{CH}$ & $1^{\prime}, 2^{\prime}, 4^{\prime}$ & $3^{\prime}$ & $1.73, \mathrm{~m}(1 \mathrm{H})$ & $25.7 \mathrm{CH}$ & $1^{\prime}, 2^{\prime}, 4^{\prime}, 5^{\prime}$ \\
\hline $4^{\prime}$ & $\begin{array}{l}1.81, \mathrm{~m}(1 \mathrm{H}) \\
1.47, \mathrm{~m}(1 \mathrm{H})\end{array}$ & $40.9 \mathrm{CH}_{2}$ & $1^{\prime}, 2^{\prime}, 3^{\prime}, 5^{\prime}, 3$ & $4^{\prime}$ & $\begin{array}{l}1.83, \mathrm{~m}(1 \mathrm{H}) \\
1.46, \mathrm{~m}(1 \mathrm{H})\end{array}$ & $40.1 \mathrm{CH}_{2}$ & $1^{\prime}, 2^{\prime}, 3^{\prime}, 5^{\prime}$ \\
\hline $5^{\prime}$ & 4.33, dt(1H,10.5, 3.5) & $50.4 \mathrm{CH}$ & $3^{\prime}, 4$ & $5^{\prime}$ & $4.19, \mathrm{~m}(1 \mathrm{H})$ & $51.6 \mathrm{CH}$ & $3^{\prime}, 4$ \\
\hline $7^{\prime}$ & & $175.2 \mathrm{C}$ & $5^{\prime}, 8^{\prime}, 9^{\prime}$ & $7^{\prime}$ & & $172.7 \mathrm{C}$ & $5^{\prime}, 8^{\prime}, 9^{\prime}$ \\
\hline $8^{\prime}$ & $4.09, \mathrm{~d}(1 \mathrm{H}, 6.5)$ & $74.2 \mathrm{CH}$ & $9^{\prime}, 10^{\prime}$ & $8^{\prime}$ & $4.43, \mathrm{~m}(1 \mathrm{H})$ & $74.4 \mathrm{CH}$ & $10^{\prime}$ \\
\hline $9^{\prime}$ & $3.76, \operatorname{dd}(1 \mathrm{H}, 4.5,1.5)$ & $75.2 \mathrm{CH}$ & $8^{\prime}, 11^{\prime}$ & $9^{\prime}$ & $4.66, \mathrm{~m}(1 \mathrm{H})$ & $87.7 \mathrm{CH}$ & $8^{\prime}, 10^{\prime}$ \\
\hline $10^{\prime}$ & $3.88, \mathrm{~m}(1 \mathrm{H})$ & $57.8 \mathrm{CH}$ & $8^{\prime}, 9^{\prime}, 11^{\prime}, 12^{\prime}$ & $10^{\prime}$ & $4.80, \mathrm{~m}(1 \mathrm{H})$ & $59.7 \mathrm{CH}$ & $14^{\prime}$ \\
\hline $11^{\prime}$ & $2.22, \mathrm{~m}(1 \mathrm{H})$ & $\mathrm{H}_{2}$ & $9^{\prime} \cdot 10^{\prime} \cdot 12^{\prime}$ & $11^{\prime}$ & $3.09, \mathrm{~d}(1 \mathrm{H}, 6.5)$ & $51.9 \mathrm{CH}$ & $10^{\prime}, 14^{\prime}$ \\
\hline & $2.16, \mathrm{~m}(1 \mathrm{H})$ & & $9^{\prime}, 10^{\prime}, 12$ & $12^{\prime}$ & & $177.4 \mathrm{C}$ & $9^{\prime}, 10^{\prime}, 11^{\prime}$ \\
\hline & $2.36, \mathrm{~m}(1 \mathrm{H})$ & 31. & & $13^{\prime}$ & $1.19, \mathrm{~d}(3 \mathrm{H}, 5.5)$ & $17.1 \mathrm{CH}_{3}$ & $14^{\prime}$ \\
\hline $12^{\prime}$ & $2.23, \mathrm{~m}(1 \mathrm{H})$ & & $11^{\prime}$ & $14^{\prime}$ & $3.76, \mathrm{dd}(1 \mathrm{H}, 5.5,11.0)$ & $64.6 \mathrm{CH}$ & $11^{\prime}, 13^{\prime}, 18^{\prime}$ \\
\hline $13^{\prime}$ & & $181.5 \mathrm{C}$ & $10^{\prime}, 11^{\prime}, 12^{\prime}$ & $15^{\prime}$ & & $78.1 \mathrm{C}$ & $11^{\prime}, 13^{\prime}, 14^{\prime}, 18^{\prime}$ \\
\hline & & & & $16^{\prime}$ & & $172.1 \mathrm{C}$ & $17^{\prime}$ \\
\hline & & & & $17^{\prime}$ & $2.05, \mathrm{~s}(3 \mathrm{H})$ & $22.3 \mathrm{CH}_{3}$ & $16^{\prime}$ \\
\hline & & & & $18^{\prime}$ & $1.44, \mathrm{~s}(3 \mathrm{H})$ & $30.2 \mathrm{CH}_{3}$ & $11^{\prime}, 14^{\prime}$ \\
\hline
\end{tabular}

Compound 5 was isolated as an amorphous solid. The ESI-MS/MS spectrum of the precursor ion $[\mathrm{M}+\mathrm{H}]^{+}$was dominated by common ion peaks at $m / z 372.1,250.1,233.1$, and 215.1 (Figure 2B). The 1D NMR data $\left({ }^{1} \mathrm{H}\right.$ and ${ }^{13} \mathrm{C}$ NMR, Table 2) and 2D NMR $\left({ }^{1} \mathrm{H}_{-}{ }^{1} \mathrm{H}\right.$ COSY and HSQC data) suggested the presence of 26 carbons, including four carbonyl carbons, six aromatic carbons, two methylenes, two methines, five methyls, and seven carbons bonded to nitrogen or oxygen. These data revealed that compound 5 possessed structural similarities to the $14^{\prime}, 15^{\prime}$-methyl-15'-hydroxypyrrolidine amicoumacin $\mathrm{C}$, but differed from the molecular formula of $14^{\prime}, 15^{\prime}$-methyl-15'-hydroxypyrrolidine amicoumacin $C$ by the addition of $-\mathrm{COCH}_{3}$ [21]. This acetyl group was identified by a distinct singlet peak observed at $\delta_{\mathrm{H}} 2.05$ in the ${ }^{1} \mathrm{H}$ NMR spectrum and a carbonyl carbon $\left(\delta_{\mathrm{C}} 172.1\right)$ in the ${ }^{13} \mathrm{C}$ NMR spectrum, which was supported by the HMBC correlation between $\mathrm{H}-17^{\prime}\left(\delta_{\mathrm{H}} 2.05\right.$, s) and carbonyl carbon $\mathrm{C}-16^{\prime}\left(\delta_{\mathrm{C}} 172.1\right)$. The ${ }^{1} \mathrm{H}-{ }^{1} \mathrm{H}$ COSY correlations from $\mathrm{H}-13^{\prime}\left(\delta_{\mathrm{H}}\right.$ $1.19, \mathrm{~d}, 5.5)$ to $\mathrm{H}-14^{\prime}\left(\delta_{\mathrm{H}} 3.76, \mathrm{dd}, 5.5,11.0\right)$, and $\mathrm{HMBC}$ correlations of $\mathrm{H}-13^{\prime} / \mathrm{H}-14^{\prime}$ and $\mathrm{HMBC}$ correlations from $\mathrm{H}-13^{\prime}\left(\delta_{\mathrm{H}} 1.19\right)$ and $\mathrm{H}-18^{\prime}\left(\delta_{\mathrm{H}} 1.44\right)$ toC- $-15^{\prime}\left(\delta_{\mathrm{C}} 78.1\right)$ suggested that the acetyl group was positioned at $\mathrm{C}-15^{\prime}$ (Figure $2 \mathrm{C}$ ). The relative configuration of compound 5 was determined by NOESY correlations of $\mathrm{H}-3 / \mathrm{H}-4^{\prime}, \mathrm{H}-5^{\prime} / \mathrm{H}-8^{\prime}, \mathrm{H}-8^{\prime} / \mathrm{H}-11^{\prime}$, $\mathrm{H}-11^{\prime} / \mathrm{H}-18^{\prime}$, and $\mathrm{H}-14^{\prime} / \mathrm{H}-18$, which shared similar stereochemical configurations with $14^{\prime}$, $15^{\prime}$-methyl-15'-hydroxypyrrolidine amicoumacin C. Thus, compound 5 was also assigned as a new amicoumacin derivative, and was named amicoumacin $\mathrm{E}$ for the first time.

Comparison of the 1D and 2D NMR data with the references confirmed that the structures of some compounds were the same as some known compounds, such as N-butanonylamicoumacin C, 6, amicoumacin A-C, 7-9, bacilosarcin A-C, 10-12, N-acetylamicoumacin B, C, 13, 14, AI-77-H, 15, and lipoamicoumacins B, 16 [20,22-25]. Compound 6 was identified as a new natural amicoumacin, which is referred to herein as $\mathrm{N}$-butanonylamicoumacin C. 


\subsection{Direct Cloning and Heterologous Expression of NRPS/PKS Gene Cluster}

To connect the NRPS/PKS gene cluster with amicoumacin biosynthesis, we direct cloned these DNA regions into E. coli plasmids using ExoCET and LLHR. Using the cloning vector $\mathrm{p} 15 \mathrm{~A}-\mathrm{cm}-$ tet $^{\mathrm{R}}-c c d B-h y g$ as the template, we designed a pair of primers carrying the terminal 62-bp homology arms of the NRPS/PKS gene cluster. The $5^{\prime}$ and $3^{\prime}$ homology arms were selected at the locations of the restriction enzymes site SpeI and PacI flanking the gene cluster. Using ExoCET, this biosynthetic gene cluster was successfully cloned into the cloning vector, and the efficiency $2 / 13$ verified by restriction enzyme analysis (Figure S19A). The resulting recombinant plasmids containing the NRPS/PKS gene cluster were designated as p15A-cm-ami. Consistent with the close genetic relationship between the native host and the heterologous host, the NRPS/PKS gene cluster was under the control of its original promoters.

The recombinant plasmid p15A-cm-ami was transferred into E. coli GB05-MtaA by electroporation, and verified by restriction enzyme analysis, to obtain E. coli GB05-MtaAami. The correct transformants were subsequently fermented, and crude extracts were analyzed using HPLC-MS to detect the products. The resulting transformants successfully produced two amicoumacins-amicoumacin A $\left(\mathrm{m} / z 424.2006[\mathrm{M}+\mathrm{H}]^{+}\right)$and amicoumacin $\mathrm{C}\left(\mathrm{m} / \mathrm{z} 407.17[\mathrm{M}+\mathrm{H}]^{+}\right.$-at levels 100 -fold less than that in the native B. subtilis fmb60 strain (Figure 3A). This result indicated that the NRPS/PKS locus encodes amicoumacin biosynthesis. However, only two amicoumacins were obtained, and the biosynthetic pathways of all other amicoumacins require further investigation.
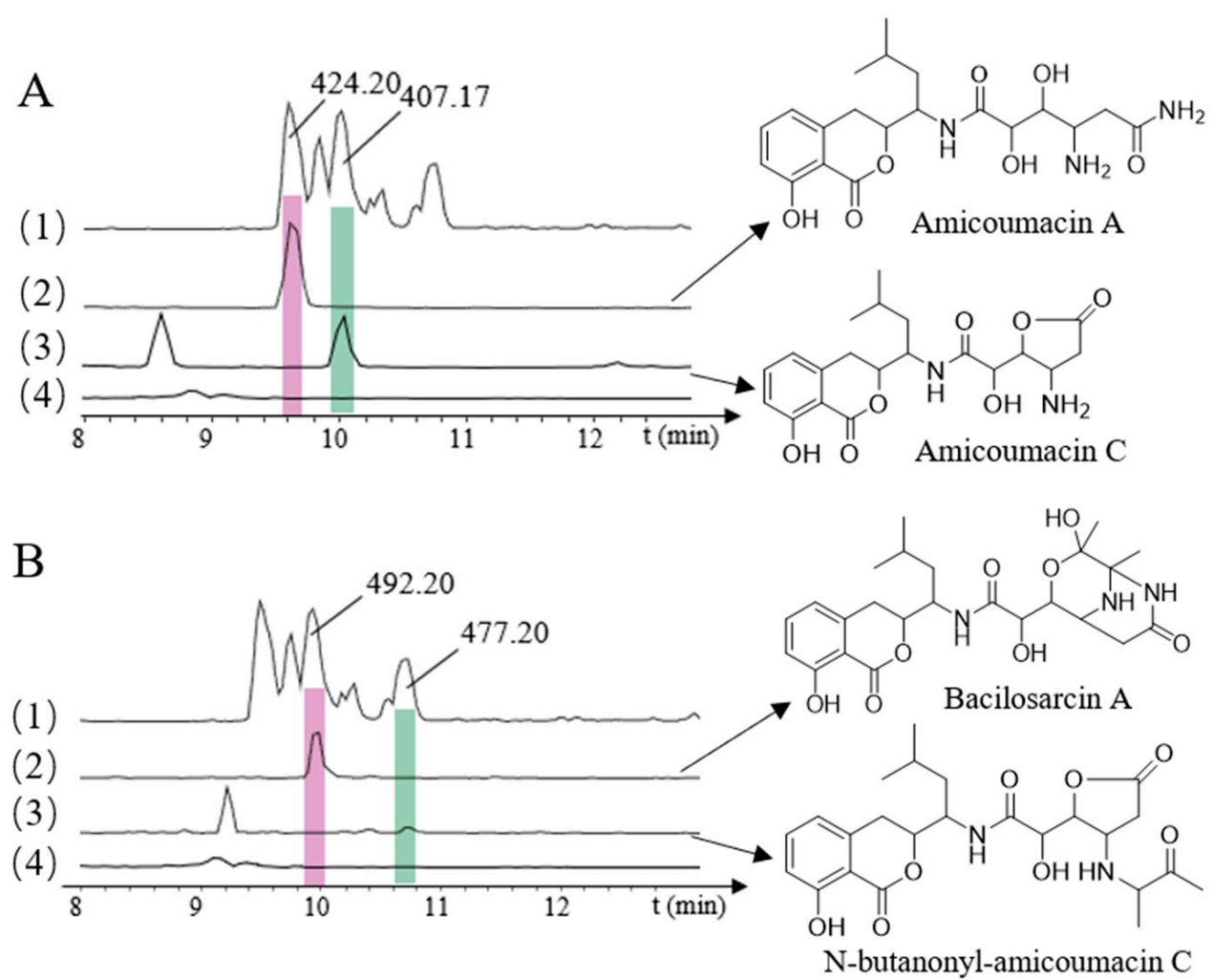

Figure 3. HPLC-MS analyses of heterologously produced amicoumacins. (A): (1) B. subtilis fmb60, (All MS); (2) Amicoumacin A ( $m / z$ 424.20) (3) Amicoumacin C ( $m / z$ 407.17); (4) E. coli GB05-MtaA, blank; (B): (1) B. subtilis fmb60, (All MS); (2) Bacilosarcin A ( $m / z$ 492.20); (3) N-butanonyl-amicoumacin C (m/z 477.20); (4) E. coli GB05-MtaA, blank. 


\subsection{Direct Cloning and Heterologous Expression of NRPS/PKS Gene Cluster and ace Gene Cluster}

Using the cloning vector pBR322-apra-OriT and genomic DNA as the template, we designed two pairs of primers to amplify the pBR322-apra cloning vector and the ace gene cluster. The resulting recombinant plasmids containing the ace gene cluster were designated as pBR322-apra-ace (Figure S19B). The recombinant plasmid pBR322-apra-ace was transferred into E. coli GB05-MtaA-ami by electroporation and verified by restriction enzyme analysis, to obtain E. coli GB05-MtaA-ami-ace [26]. It was found that after adding the ace gene cluster, compared with the NRPS/PKS gene cluster alone, bacilosarcin A $\left(\mathrm{m} / z\right.$ 492.20 $\left.[\mathrm{M}+\mathrm{H}]^{+}\right)$and N-butanonyl-amicoumacin $\mathrm{C}\left(\mathrm{m} / z\right.$ 477.20 $\left.[\mathrm{M}+\mathrm{H}]^{+}\right)$were identified (Figure 3B). Bacilosarcin B and bacilosarcin A, N-butanonyl-amicoumacin C can be synthesized using the same substrate, indicating that the ace gene cluster plays a key role in the biosynthesis of amicoumacins.

\subsection{Antimicrobial Bioassay of Lipoamides and Amicoumacins}

The antimicrobial activities of lipoamides, amicoumacins, and erythromycin gluceptate were evaluated in vitro using a broth microdilution method. As shown in Table 3, lipoamides D-F, amicoumacin A, and bacilosarcin B produced significant inhibition against S. aureus ATCC25923, M. luteus CMCC 28001, B. pumilus CMCC 63202, B. cereus ATCC 14579, L. monocytogenes CICC 21662, and S. aureus MRSA, with MIC values ranging from 1.56 to $25 \mu \mathrm{g} / \mathrm{mL}$. In particular, the MIC values against $S$. aureus MRSA were $6.25 \mu \mathrm{g} / \mathrm{mL}$ for amicoumacin A and $3.13 \mu \mathrm{g} / \mathrm{mL}$ for bacilosarcin B. However, amicoumacins D, E and other isolated compounds were found to be weakly active or inactive at $100 \mu \mathrm{g} / \mathrm{mL}$.

Table 3. MIC values of lipomide D-F, 1-3, amicoumacin A, 7, and bacilosarcin B, 11, toward selected microorganisms $(\mu \mathrm{g} / \mathrm{mL})$.

\begin{tabular}{|c|c|c|c|c|c|c|}
\hline Microorganism & Erythromycin Gluceptate & Lipomide D & Lipomide E & Lipomide F & Amicoumacin A & Bacilosarcin B \\
\hline S. aureus ATCC 25923 & 0.10 & 12.5 & 12.5 & 12.5 & 1.56 & 1.56 \\
\hline M. luteus CMCC 28001 & 0.39 & 25 & 25 & 25 & 1.56 & 1.56 \\
\hline B. pumilus CMCC 63202 & 1.56 & 12.5 & 12.5 & 12.5 & 3.13 & 1.56 \\
\hline B. cereus ATCC 14579 & 3.12 & 6.25 & 6.25 & 6.25 & 1.56 & 1.56 \\
\hline L. monocytogenes CICC 21662 & 0.39 & 12.5 & 12.5 & 12.5 & 1.56 & 3.13 \\
\hline S. aureus MRSA & 1.56 & 12.5 & 12.5 & 12.5 & 6.25 & 3.13 \\
\hline P. fluorescens ATCC 49642 & 0.78 & $>100$ & $>100$ & $>100$ & 6.25 & 6.25 \\
\hline E. coli ATCC 25922 & 50 & $>100$ & $>100$ & $>100$ & 100 & 100 \\
\hline
\end{tabular}

ATCC: American Type Culture Collection, CMCC: China Center of Medicine Culture Collection, CICC: China Center of Industrial Culture Collection. Multidrug-resistant S. aureus (MRSA) was isolated from Jiangsu Province Hospital.

\subsection{Assay of FRAP Activities and ABTS $^{+}$Radical Scavenging}

The antioxidant activities of the amicoumacins were tested according to their FRAP activities and $\mathrm{ABTS}^{+}$radical scavenging assays (Figure 4A,B). Amicoumacin E, $N$-acetylmethyamicoumacin $\mathrm{C}, \mathrm{N}$-acetylamicoumacin B, AI-77-H, and lipoamicoumacins B showed significant FRAP activities and $\mathrm{ABTS}^{+}$radical scavenging activities at a concentration of 1 $\mathrm{mg} / \mathrm{mL}$. In the $\mathrm{ABTS}^{+}$radical scavenging assay, amicoumacin $\mathrm{E}, \mathrm{N}$-butanonyl-amicoumacin C, N-acetylamicoumacin B, AI-77-H, and lipoamicoumacins B scavenged 38.8\%,55.9\%, $48.9 \%, 64.5 \%$, and $69.9 \%$ of ABTS $^{+}$radicals, respectively. Other amicoumacins had limited antioxidant activities at the same concentration. Furthermore, the antioxidant activities of all amicoumacins were weaker than those of Trolox (lipoamides not tested). 
A

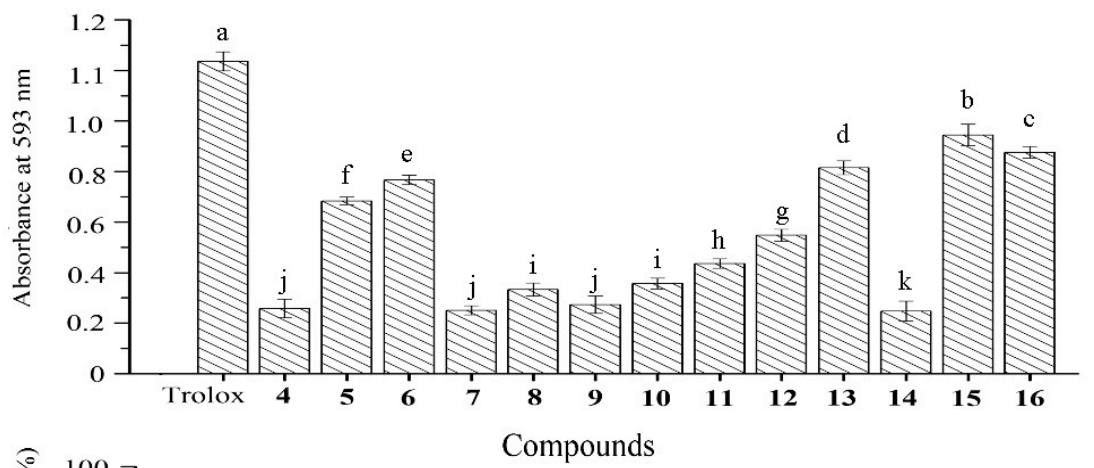

B

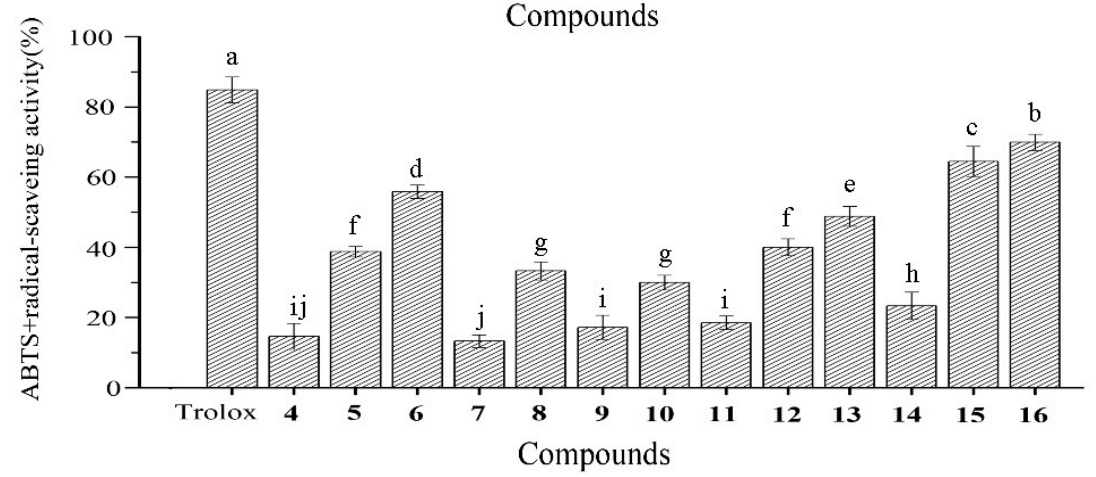

Figure 4. (A) FRAP activity and (B) $\mathrm{ABTS}^{+}$radical-scavenging activity of the isolated compounds. Amicoumacin D, 4, E, 5, N-butanonyl-amicoumacin C, 6, amicoumacin A-C, 7-9, bacilosarcin A-C, 10-12, N-acetylamicoumacin B-C, 13-14, AI-77-H, 15, lipoamicoumacins B, 16. Results labeled with different lowercase letters $(a-k)$ within each column indicate significant differences $(p<0.05)$.

\section{Discussion}

B. subtilis has significant metabolic capabilities and versatile biochemical mechanisms, because of its production of structurally diverse bioactive chemical structures $[27,28]$. Recent microarray-based comparative genomic analyses have revealed that members of this species also have diverse genomic properties [29]. There are about 700 Bacillus sp. genomes available on the NCBI website. Thus, the genomes presented here can guide the in-depth investigation of other $B$. subtilis metabolites. The genome sequence and analysis of $B$. subtilis fmb60 showed that a variety of clusters were involved in the production of bioactive compounds.

In the present work, five novel lipoamides and amicoumacins were identified from B. subtilis fmb60 by genome-directed isolation. Amicoumacins belong to a family of 3 , 4-dihydroisocoumarin derivatives produced by the genus Bacillus, which have shown antibacterial, anti-inflammatory, and antiulcer activities and potent gastroprotective and antiulcerogenic activities [30,31]. To identify the genetic determinants of lipoamide and amicoumacins biosynthesis in B. subtilis fmb60, the NRPS/PKS gene cluster of B. subtilis fmb60 genome was submitted to BLAST. Our analysis indicated that the hybrid NRPS/PKS gene cluster was similar to that of the ami gene cluster synthase. ami was identified in earlier studies as the amicoumacin A biosynthetic gene cluster from B. subtilis 1779 [32]. Thus, the hybrid NRPS/PKS gene cluster could be plausibly assigned to the biosynthetic gene cluster for amicoumacins and lipoamides, which were isolated from B. subtilis fmb60.

Heterologous expression is a strategy for natural product discovery, and Red/ET recombineering has been widely used for direct cloning of biosynthetic pathways. The ExoCET method was used to direct clone the NRPS/PKS gene cluster of $B$. subtilis fmb60 and subsequently expressed it in the heterologous host E. coli GB05-MtaA. Two amicoumacins were obtained, which further verified that NRPS/PKS gene cluster is crucial for the biosynthesis of the amicoumacins.

However, the synthesis mechanism of other amicoumacins has not been reported yet. Previous reports indicated that this may in part be due to the possibility that many of 
the amicoumacin analogues discussed here may be isolated artifacts [4]. The formation mechanism of the 2-hydroxymorpholine moiety, an unusual cyclic structure in bacilosarcin, cannot be elucidated only by bioinformatics analysis [33]. Previous studies reported that chemical synthesis of bacilosarcins has been accomplished from amicoumacin $\mathrm{C}$, using diastereoselective reductive amination of amicoumacin $C$ with acetoin to form the corresponding $N$-butanonyl-amicoumacin $C[21,34]$. Therefore, the diastereomeric mixture of $\mathrm{N}$-butanonyl-amicoumacin $\mathrm{C}$ is the core intermediate in the synthesis of bacilosarcin. In this study, $\mathrm{N}$-butanonyl-amicoumacin $\mathrm{C}$ was identified in $B$. subtilis fmb60 fermentation broth for the first time. Acetoin is also an important physiological metabolic product excreted from B. subtilis [35]. Thus, it is presumed that bacilosarcins from B. subtilis are also synthesized using the aforementioned pathway under the catalysis of different enzymes. We used exonuclease combined with ExoCET technology to clone the NRPS/PKS and ace gene clusters into E. coli. We found that heterologous co-expression strains can synthesize bacilosarcin A and N-butanonyl-amicoumacin C, bacilosarcin B, bacilosarcin A, and $\mathrm{N}$ butanonyl-amicoumacin $C$ from the same substrate, indicating that the ace gene cluster is related to the biosynthesis of bacilosarcins.

For amicoumacin D, Gln was recognized by the amiI domain of the NRPS/PKS gene cluster instead of Asn, resulting in the synthesis of bacillmacin A. The synthesis of $\mathrm{N}$ acetylamicoumacin $\mathrm{A}-\mathrm{C}$ from $\mathrm{X}$. boviensis was mainly related to $N$-acetyltransferase, and $B$. subtilis also synthesized metabolites with a structure similar to that of $\mathrm{N}$-acetylamicoumacin A-C. This study also assumed that $N$-acetyltransferase in $B$. subtilis may take part in the synthesis process [36]. However, focusing on the hybrid NRPS/PKS gene cluster of $B$. subtilis fmb60, no domain related to $N$-acetyltransferase synthesis was found near the genome. Therefore, it is presumed that the synthesis of $N$-acetylamicoumacin $B$ and $C$ in $B$. subtilis may be mediated by the isomerase or through post-modification. Furthermore, the biosynthetic pathways of amicoumacin E still need further investigation.

\section{Materials and Methods}

\subsection{Bacterial Strains and Culture Conditions}

B. subtilis fmb60 was isolated from the straw compost of Nanjing. B. subtilis fmb60 colonies and transferred to solid medium nutrient agar. B. subtilis fmb60 was cultured in beef peptone yeast medium at $37^{\circ} \mathrm{C}$ for $16 \mathrm{~h}$ as seeds. One milliliter of seed culture was inoculated into $300 \mathrm{~mL}$ of Landy medium in a $1 \mathrm{~L}$ shake-flask and cultured in a shaking incubator (speed: $180 \mathrm{rpm}$ ) at $33^{\circ} \mathrm{C}$ for $36 \mathrm{~h}$.

\subsection{Genome Sequencing, Annotation, and Bioinformatics Analysiszz}

The genome of $B$. subtilis fmb60 was sequenced using the third-generation singlemolecule sequencing machine PacBio RS II (PacBio, Menlo Park, CA, USA) by Shanghai Hanyu Bio-Tech (Shanghai, China). Total genomic DNA was extracted using bacterial DNA kits (Omega Bio-Tek, USA). The extracted DNA was fragmented to $10 \mathrm{~kb}$ using Covaris ${ }^{\circledR}$ g-TUBE $^{\circledR}$ (Covaris, Woburn, MA, USA). Subsequently, the DNA fragment library used as the template for sequencing was constructed using PacBio ${ }^{\circledR}$ SMRTbell ${ }^{\mathrm{TM}}$ Template Prep Kits (PacBio, Menlo Park, CA, USA). After sequencing, the fragments were assembled to reconstruct the complete genome of B. subtilis fmb60. The bioinformatics program antiSMASH 5.2.0 (Kai Blin, Kgs. Lyngby, Denmark) was initially used to analyze the whole draft genome sequence [37].

\subsection{Isolation and Purification of Lipoamides and Amicoumacins}

To isolate the lipoamides from B. subtilis fmb60, the fermentation broth was centrifuged for $15 \mathrm{~min}$ at $10,000 \times \mathrm{g}$. The supernatant was collected and adjusted to $\mathrm{pH} 2.0$ with $\mathrm{HCl}$. After acid precipitation at $4{ }^{\circ} \mathrm{C}$ for $12 \mathrm{~h}$, the supernatant was collected by centrifuging at $10,000 \times g$ for $15 \mathrm{~min}$. Then, the supernatant was extracted twice with the same volume of ethyl acetate, and the solvent was removed under reduced pressure at $50{ }^{\circ} \mathrm{C}$ to dryness. The 
dry matter was dissolved in methanol and centrifuged to collect the supernatant containing the crude substances.

The crude substances generated using the method described above were processed using a semipreparative HPLC system (Waters 600, Milford, MA, USA) to collect fractions from the subfractions. One milliliter of crude extract solution was loaded and separated on a column $(150 \times 10 \mathrm{~mm}$ i.d., $5 \mu \mathrm{m}, \mathrm{C} 18$, Waters; flow rate: $6 \mathrm{~mL} / \mathrm{min}$; detection: $210 \mathrm{~nm})$ from different subfractions using an isocratic program with acetonitrile $-\mathrm{H}_{2} \mathrm{O}(v / v)$ as the eluent. Finally, three novel compounds 1-3 were isolated, and ESI-HRMS analysis showed intense pseudo-molecular ions $[\mathrm{M}+\mathrm{H}]^{+}$at $m / z 329.2452,315.2295$, and 343.2604 for these three compounds.

To isolate the amicoumacins from $B$. subtilis fmb60, the acidified supernatant was adjusted to $\mathrm{pH} 7.0$ with $\mathrm{NaOH}$. The supernatant was then extracted with the same volume of ethyl acetate. The solvent was evaporated under reduced pressure at $50{ }^{\circ} \mathrm{C}$ to dryness. The dry matter was dissolved in methanol to collect the supernatant containing the crude substances. The crude extract was subjected to Sephadex LH-20 column chromatography $(\Phi 2.6 \times 100 \mathrm{cmi}$.d., Sigma, St. Louis, MO, USA) for further separation. The eluent was $\mathrm{MeOH}-\mathrm{H}_{2} \mathrm{O}(4: 1, v / v)$ and the flow rate was $12 \mathrm{~mL} / \mathrm{h}$. The eluent fraction was purified by Nexera X2 HPLC (SHIMADZU, Kyoto, Japan) with a gradient mobile phase (acetonitrile $-\mathrm{H}_{2} \mathrm{O}$, from $50 \%$ to $60 \%$; column: $150 \times 10 \mathrm{~mm}$ i.d., $5 \mu \mathrm{m}, \mathrm{C} 18$, Waters; flow rate: $4 \mathrm{~mL} / \mathrm{min}$; detection: $250 \mathrm{~nm}$ ) to yield compounds $\mathbf{4 - 1 6}$.

\subsection{Determination of Amicoumacins by HPLC-MS}

For liquid chromatography high-resolution mass spectrometry (LC-HRMS) analysis, an UltiMate 3000 HPLC system (Dionex, Sunnyvale, CA, USA) equipped with a C18 column $(5 \mu \mathrm{m}, 4.6 \times 250$ mm i.d., Agilent Technologies, Palo Alto, CA, USA) was used. The spray voltage was set to $4.0 \mathrm{kV}$, and the heated transfer capillary temperature was set to $350{ }^{\circ} \mathrm{C}$. High-resolution mass spectrometry analysis was performed with a Thermo Finnigan Surveyor-LCQ DECA XP Plus (Thermo Electron Corporation, San Jose, CA, USA) equipped with an electrospray ionization (ESI) source.

\subsection{NMR Spectroscopy Identification}

The structures were identified by nuclear magnetic resonance (NMR) spectroscopy, and the samples were carried out in methanol- $d_{4}$ on Avance 600, 500, and $300 \mathrm{MHz}$ Bruker NMR spectrometer (Bruker, Faellanden, Switzerland).

Lipoamide D (1): amorphous solid, UV (MeOH) $\lambda_{\max }(\log \varepsilon) 210$ (2.10), 248 (0.53), 315

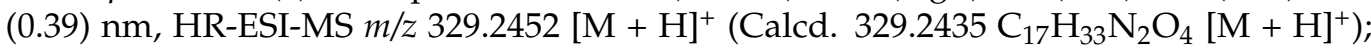
Soluble, methanol, DMSO, $\mathrm{CHCl}_{3}$, ethyl acetate; insoluble/poorly soluble in water.

Lipoamide $E$ (2): amorphous solid, UV (MeOH) $\lambda_{\max }(\log \varepsilon) 210$ (2.08), 248 (0.51), 315 (0.37) nm, HR-ESI-MS m/z 315.2295 [M + H] ${ }^{+}$(Calcd. $315.2278 \mathrm{C}_{16} \mathrm{H}_{31} \mathrm{~N}_{2} \mathrm{O}_{4}[\mathrm{M}+\mathrm{H}]^{+}$); Soluble, methanol, $\mathrm{DMSO}, \mathrm{CHCl}_{3}$, ethyl acetate; insoluble/poorly soluble in water.

Lipoamide $F(3)$ : amorphous solid, UV (MeOH) $\lambda_{\max }(\log \varepsilon) 210$ (2.10), 248 (0.55), 315 (0.40) nm, HR-ESI-MS m/z [M + H] ${ }^{+} 343.2604$ (Calcd. $343.2591 \mathrm{C}_{18} \mathrm{H}_{35} \mathrm{~N}_{2} \mathrm{O}_{4}[\mathrm{M}+\mathrm{H}]^{+}$); Soluble, methanol, DMSO, $\mathrm{CHCl}_{3}$, ethyl acetate; insoluble/poorly soluble in water.

Amicoumacin D (4): amorphous solid, $[\alpha]^{23} \mathrm{D}^{-93.2^{\circ}}$ (c 0.1, $\left.\mathrm{MeOH}\right) ; \mathrm{UV}(\mathrm{MeOH}) \lambda_{\max }$ $(\log \varepsilon) 203$ (4.43), 246 (3.74), 314 (3.54) nm, HR-ESI-MS m/z 421.1971 [M + H] ${ }^{+}$(Calcd. $421.1975 \mathrm{C}_{21} \mathrm{H}_{29} \mathrm{~N}_{2} \mathrm{O}_{7}[\mathrm{M}+\mathrm{H}]^{+}$); Soluble, methanol, DMSO, $\mathrm{CHCl}_{3}$, ethyl acetate; insoluble/poorly soluble in water.

Amicoumacin E (5): amorphous solid, $[\alpha]^{23} \mathrm{D}^{-83.7^{\circ}}(c 0.1, \mathrm{MeOH}) ; \mathrm{UV}(\mathrm{MeOH}) \lambda_{\max }$ $(\log \varepsilon) 203$ (4.42), 246 (3.70), 314 (3.44) nm, HR-ESI-MS m/z 519.2348 [M + H] ${ }^{+}$(calcd. 519.2343 $\mathrm{C}_{26} \mathrm{H}_{35} \mathrm{~N}_{2} \mathrm{O}_{9}[\mathrm{M}+\mathrm{H}]^{+}$); soluble, methanol, DMSO, $\mathrm{CHCl}_{3}$, ethyl acetate; insoluble/poorly soluble in water. 


\subsection{B. subtilis fmb60 Genomic DNA Isolation}

Genomic DNA was isolated from lysed cells by phenol-chloroform extraction and ethanol precipitation [26]. B. subtilis fmb60 was cultured in $50 \mathrm{~mL}$ of medium LB at $30^{\circ} \mathrm{C}$ overnight. After centrifugation at $8300 \times g$ for $5 \mathrm{~min}$, the cells were washed twice with $\mathrm{ddH}_{2} \mathrm{O}$, and then resuspended in $8 \mathrm{~mL}$ of SET buffer $(75 \mathrm{mM} \mathrm{NaCl}, 25 \mathrm{mM}$ EDTA, $20 \mathrm{mM}$ Tris, $\mathrm{pH}$ 8.0). After adding $10 \mathrm{mg}$ lysozyme and incubating at $37^{\circ} \mathrm{C}$ for $1-2 \mathrm{~h}$ in a water bath with occasional inverting, $500 \mu \mathrm{L}$ of proteinase $\mathrm{K}(20 \mathrm{mg} / \mathrm{mL})$ and $1 \mathrm{~mL}$ of $10 \%$ sodium dodecyl sulfate (SDS) were added, and the mixture was incubated at $50{ }^{\circ} \mathrm{C}$ with occasional inversion for $2 \mathrm{~h}$ until the solution became clear. Then, $3.5 \mathrm{~mL}$ of $5 \mathrm{M} \mathrm{NaCl}$ was added with inverting, after which $15 \mathrm{~mL}$ of phenol/chloroform/isoamyl alcohol (25:24:1) was added and mixed thoroughly by inversion to create an emulsion. After centrifugation at $8300 \times g$ for $30 \mathrm{~min}, 500 \mu \mathrm{L}$ of the aqueous phase was transferred to a new $2 \mathrm{~mL}$ tube using an end-cut wide-bore $1 \mathrm{~mL}$ tip, then $35 \mu \mathrm{L}$ of $3 \mathrm{M}$ sodium acetate $(\mathrm{pH} 7.5)$ and $1.2 \mathrm{~mL}$ of absolute ethanol were added, and gently inverted to mix. The DNA was transferred to a $1.5 \mathrm{~mL}$ tube using a blue tip, rinsed with $75 \%$ ethanol, dried at room temperature (RT) for

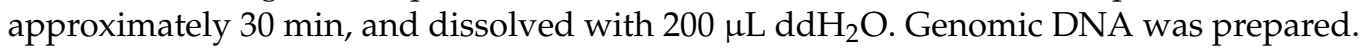

\subsection{Direct Cloning of the NRPS/PKS and ace Gene Clusters}

E. coli were cultivated and manipulated according to standard protocols. The strains and plasmids used in this study are listed in Table S1. Primer synthesis and DNA sequencing were performed at Shanghai Sangon Biotech Co., Ltd. (Shanghai, China). Restriction enzymes were purchased from New England Biolabs Ltd. (Beijing, China), DNA polymerase (PrimerSTAR and T4), and DNA marker were purchased from TAKARA Biotechnology Co., Ltd. (Dalian, China).

The genomic DNA was completely digested with the restriction enzymes PacI and SpeI to release the NRPS/PKS gene cluster. The linear cloning vector $\mathrm{p} 15 \mathrm{~A}-\mathrm{cm}$ flanked with homology arms to target genes was amplified by PCR using p15A-cm-tet ${ }^{\mathrm{R}}-\mathrm{ccdB}$ hyg as template, and primers (YM-ami-5 and YM-ami-3, Table S2) carrying the terminal homology arms to the target gene cluster. A direct cloning protocol was carried out according to our previous publication [26]. Recombinants carrying the entire gene cluster were selected by chloramphenicol resistance on the plate (the final concentration was $15 \mu \mathrm{g} / \mathrm{mL}$ ) and subsequently verified by restriction enzyme analysis and sequencing, to obtain correct recombinants.

The ace gene cluster was amplified by PCR using primers ace-F and ace-R carrying the terminal homology arms to the pBR322 cloning vector. The linear cloning vector pBR322-apra flanked with homology arms to the ace gene cluster was amplified by PCR using pBR322-apra-OriT as template and primers (ace-pBR322-HAF and ace-pBR322-HAF, Table S2) carrying the terminal homology arms to the ace gene cluster. These two fragments were recombined using RecET recombinase in strain E. coli GB05-dir. The protocol was carried out according to our previous publication [14]. Recombinants carrying the entire gene cluster were selected by apramycin resistance on the plate (the final concentration was $50 \mu \mathrm{g} / \mathrm{mL}$ ) and subsequently verified by restriction enzyme analysis and sequencing, to obtain correct recombinants.

\subsection{Heterologous Expression of NRPS/PKS and ace Gene Clusters in E. coli}

The recombinant plasmid p15A-cm-ami was transferred into E. coli GB05-MtaA by electroporation and verified by restriction enzyme analysis to obtain E. coli GB05-MtaAami [27]. The plasmid pBR322-apra-ace was transferred into E. coli GB05-MtaA-ami by electroporation to obtain recombinant E. coli GB05-MtaA-ami-ace containing the NRPS/PKS and ace gene clusters.

The correct transformants were subsequently fermented. The fermentation method for B. subtilis fmb60 is described above, while E. coli GB05-MtaA-ami and E. coli GB05MtaA-ami-ace were cultured in beef peptone yeast medium at $37^{\circ} \mathrm{C}$ overnight as seeds. One milliliter of seed culture was inoculated into a $250 \mathrm{~mL}$ shake-flask containing $50 \mathrm{~mL}$ 
of Landy medium with agitation at $200 \mathrm{rpm}$ at $30{ }^{\circ} \mathrm{C}$ for $3 \mathrm{~d}$. The extraction method is described above. The crude extract was obtained using HPLC-MS, which was carried out on a Thermo Scientific UltiMate 3000 HPLC system connected to a Bruker ESI-MSMS Impact HD operating in positive ionization mode at a scan range of $m / z 200-2000$, auto $\mathrm{MS}^{2}$ fragmentation. Reverse-phase chromatography of HPLC was carried out with $2.1 \times 100 \mathrm{~mm}, 2.2 \mu \mathrm{m}$ columns (PSLC $120 \mathrm{C} 18$ ) in a solvent gradient, with solvents A (water and $0.1 \%$ formic acid) and $\mathrm{B}$ (CH3CN and $0.1 \%$ formic acid) for $25 \mathrm{~min}$ : $5 \% \mathrm{~B}$ from 0 to $3 \mathrm{~min}, 5 \% \mathrm{~B}-95 \%$ B within $15 \mathrm{~min}$, followed by $4 \mathrm{~min}$ with $95 \% \mathrm{~B}$ and $3 \mathrm{~min}$ with $5 \% \mathrm{~B}$ at a flow rate of $0.3 \mathrm{~mL} / \mathrm{min}$. MS measurements were carried out using a standard ESI source.

\subsection{Minimal Inhibitory Concentration (MIC) Assays and the Effects of Antimicrobials on Bacterial Morphology}

The MICs of the amicoumacins were determined using a broth microdilution method according to the Clinical and Laboratory Standards Institute (CLSI) guidelines [38]. The indicator bacteria in this assay were incubated in Mueller-Hinton broth (MHB) and normalized to an optical density of $10^{6} \mathrm{CFU} / \mathrm{mL}$. The amicoumacins were two-fold serially diluted in 96-well plates of $\mathrm{MHB}$, with $50 \mu \mathrm{L}$ in each well and concentrations ranging from 0.78 to $100 \mu \mathrm{g} / \mathrm{mL}$. Then, $50 \mu \mathrm{L}$ of bacterial suspension was added to each well, with a final inoculum density of approximately $5 \times 10^{5} \mathrm{CFU} / \mathrm{mL}$, and the plates were incubated statically at $37^{\circ} \mathrm{C}$ for $24 \mathrm{~h}$ [39]. Quality control and interpretations of results were performed according to CLSI guidelines [40]. The MICs of the amicoumacins were defined as the lowest concentration of amicoumacins, where no visible growth was observed in the wells of the microtiter plates. All assays were performed in triplicate.

\subsection{Assay of $A B T S^{+}$Radical Scavenging and Ferric-Reducing Activity}

The ferric-reducing ability power (FRAP) and $\mathrm{ABTS}^{+}$radical scavenging activities of the amicoumacins were measured using commercial kits (Jiancheng Bio-engineering Institute, Nanjing, China). Trolox was used as a positive control.

\subsection{Data Processing}

SPSS 17.0 software was used for the experimental data processing. Antibacterial and antioxidant experiments were repeated three times, and the Duncan test was used for significance analysis $(p<0.05)$. All of the forms were made using Excel 2010.

\section{Conclusions}

In conclusion, five new metabolites, lipoamides D-F (1-3), amicoumacins D, E $(\mathbf{4}, \mathbf{5})$, and known metabolites (6-16), have been identified from B. subtilis fmb60. Lipoamides D-F inhibited the growth of foodborne harmful bacteria, and amicoumacins D and E have antioxidant activities. The heterologous expression results demonstrated the function of NRPS/PKS in B. subtilis fmb60, and showed that the ace gene cluster can participate in the synthesis of amicoumacins.

Supplementary Materials: The following are available online. Table S1. Strains and plasmids in this study. Table S2. Primers used in this study. Table S3. Secondary metabolite biosynthetic gene clusters of B. subtilis fmb60. Table S4. NRPS/PKS gene clusters of B. subtilis fmb60. Figures S1-S18. 1D and 2D NMR spectra of lipoamide D, $\mathbf{1}$, amicoumacin D, 4, amicoumacin E, $\mathbf{5}$ in methanol- $d_{4}$. Figure S19. Digestion map of NRPS/PKS and the ace gene cluster.

Author Contributions: J.Y. performed the experiments, analyzed the data, and wrote the manuscript; Q.Z., F.X., and M.Y. analyzed the data and wrote the manuscript; H.D. and X.B. analyzed and discussed the data; Z.L. provided samples and discussed the data; Y.L. and F.L. designed the research content, analyzed the data, and modified the manuscript. All authors have read and agreed to the published version of the manuscript. 
Funding: This work was financially supported by grants from the National Key R\&D Program of China (No. 2019YFA0905700), China Postdoctoral Science Foundation (No. 2019M661767), National Natural Science Foundation of China (No. 31571887), Jiangsu Planned Projects for Postdoctoral Research Funds (No.2019K015), Priority Academic Program Development of Jiangsu Higher Education Institutions (PAPD), and The Research and Practice Innovation Program for College Graduates of Jiangsu Province (No. KYCX20_2888).

Institutional Review Board Statement: Not applicable.

Informed Consent Statement: Not applicable.

Data Availability Statement: The authors declare that all data generated or analyzed during this study are included in this published article.

Conflicts of Interest: The authors declare that they have no conflict of interest.

Sample Availability: Samples of the lipoamides and amicoumacins are available from the authors.

\section{References}

1. Guan, Z.; Xue, D.; Abdallah, I.I.; Dijkshoorn, L.; Setroikromo, R.; Lv, G.; Quax, W.J. Metabolic engineering of Bacillus subtilis for terpenoid production. Appl. Microbiol. Biotechnol. 2015, 99, 9395-9406. [CrossRef] [PubMed]

2. Shafi, J.; Tian, H.; Ji, M. Bacillus species as versatile weapons for plant pathogens: A review. Biotechnol. Biotechnol. Equip. 2017, 31, 446-459. [CrossRef]

3. Stein, T. Bacillus subtilis antibiotics: Structures, syntheses and specific functions. Mol. Microbiol. 2005, 56, 845-857. [CrossRef] [PubMed]

4. Kaspar, F.; Neubauer, P.; Gimpel, M. Bioactive secondary metabolites from Bacillus subtilis: A comprehensive review. J. Nat. Prod. 2019, 82, 2038-2053. [CrossRef]

5. Guo, S.; Li, X.; He, P.; Ho, H.; Wu, Y.; He, Y. Whole-genome sequencing of Bacillus subtilis XF-1 reveals mechanisms for biological control and multiple beneficial properties in plants. J. Ind. Microbiol. Biotechnol. 2015, 42, 925-937. [CrossRef]

6. Wang, Z.J.; Zhou, H.; Zhong, G.; Huo, L.J.; Tang, Y.J.; Zhang, Y.M.; Bian, X.Y. genome mining and biosynthesis of primary amine-acylated desferrioxamines in a marine gliding bacterium. Org. Lett. 2020, 22, 939-943. [CrossRef] [PubMed]

7. Winter, J.M.; Behnken, S.; Hertweck, C. Genomics-inspired discovery of natural products. Curr. Opin. Chem. Biol. 2011, 15, 22-31. [CrossRef] [PubMed]

8. Dunlap, C.A.; Bowman, M.J.; Schisler, D.A. Genomic analysis and secondary metabolite production in Bacillus amyloliquefaciens AS 43.3: A biocontrol antagonist of fusarium head blight. Biol. Control. 2013, 64, 166-175. [CrossRef]

9. Wen, Y.; Wu, X.; Teng, Y.; Qian, C.; Zhan, Z.; Zhao, Y.; Li, O. Identification and analysis of the gene cluster involved in biosynthesis of paenibactin, a catecholate siderophore produced by Paenibacillus elgii B69. Environ. Microbiol. 2011, 13, 2726-2737. [CrossRef]

10. Nikolouli, K.; Mossialos, D. Bioactive compounds synthesized by non-ribosomal peptide synthetases and type-I polyketide synthases discovered through genome-mining and metagenomics. Biotechnol. Lett. 2012, 34, 1393-1403. [CrossRef]

11. Mizuno, C.M.; Kimes, N.E.; López-Pérez, M.; Ausó, E.; Rodriguez-Valera, F.; Ghai, R. A hybrid NRPS-PKS gene cluster related to the bleomycin family of antitumor antibiotics in Alteromonas macleodii strains. PLoS ONE 2013, 8, e76021.

12. Ugai, T.; Minami, A.; Gomi, K.; Oikawa, H. Genome mining approach for harnessing the cryptic gene cluster in Alternaria solani: Production of PKS-NRPS hybrid metabolite, didymellamide B. Tetrahedron Lett. 2016, 57, 2793-2796. [CrossRef]

13. Reimer, D.; Bode, H.B. A natural prodrug activation mechanism in the biosynthesis of nonribosomal peptides. Nat. Prod. Rep. 2014, 31, 154-159. [CrossRef] [PubMed]

14. Fu, J.; Bian, X.Y.; Hu, S.B.; Wang, H.L.; Huang, F. Full-length rece enhances linear-linear homologous recombination and facilitates direct cloning for bioprospecting. Nat. Biotechnol. 2012, 30, 440-446. [CrossRef] [PubMed]

15. Wang, H.L.; Li, Z.; Jia, R.N.; Yin, J.; Li, A.Y.; Xia, L.Q.; Yin, Y.L.; Müller, R.; Fu, J.; Stewart, A.F.; et al. ExoCET: Exonuclease in vitro assembly combined with RecET recombination for highly efficient direct DNA cloning from complex genomes. Nucleic Acids Res. 2018, 46, e28. [CrossRef] [PubMed]

16. Yang, J.; Zhu, X.; Cao, M.; Wang, C.; Zhang, C.; Lu, Z.; Lu, F. Genomics-inspired discovery of three antibacterial active metabolites, aurantinins B, C, and D from compost-associated Bacillus subtilis fmb60. J. Agric. Food Chem. 2016, 64, 8811-8820. [CrossRef] [PubMed]

17. Song, J.Y.; Kim, H.A.; Kim, J.S.; Kim, S.Y.; Jeong, H.; Kang, S.G.; Kim, B.K.; Kwon, S.K.; Lee, C.H.; Yu, D.S. Genome sequence of the plant growth-promoting rhizobacterium Bacillus sp. strain JS. J. Bacteriol. 2012, 194, 3760-3761. [CrossRef]

18. Zhou, T.; Zeng, H.; Qiu, D.; Yang, X.; Wang, B.; Chen, M.; Guo, L.; Wang, S. Global transcriptional responses of Bacillus subtilis to xenocoumacin 1. J. Appl. Microbiol. 2011, 111, 652-662. [CrossRef] [PubMed]

19. Park, D.; Ciezki, K.; Van, D.H.R.; Singh, S.; Reimer, D.; Bode, H.B.; Forst, S. Genetic analysis of xenocoumacin antibiotic production in the mutualistic bacterium Xenorhabdus nematophila. Mol. Microbiol. 2009, 73, 938-949. [CrossRef]

20. Berrue, F.; Ibrahim, A.; Boland, P.; Kerr, R.G. Newly isolated marine Bacillus pumilus (SP21): A source of novel lipoamides and other antimicrobial agents. Pure Appl. Chem. 2009, 81, 1027-1031. [CrossRef] 
21. Brotherton, C.A.; Balskus, E.P. A prodrug resistance mechanism is involved in colibactin biosynthesis and cytotoxicity. J. Am. Chem. Soc. 2013, 135, 3359-3362. [CrossRef] [PubMed]

22. Li, Y.; Xu, Y.; Liu, L.; Han, Z.; Lai, P.Y.; Guo, X.; Zhang, X.; Lin, W.; Qian, P.Y. Five new amicoumacins isolated from a marine-derived bacterium Bacillus subtilis. Mar. Drugs 2012, 10, 319-328. [CrossRef] [PubMed]

23. Itoh, J.; Omoto, S.; Nishizawa, N.; Kodama, Y.; Inouye, S. Chemical structures of amicoumacins produced by Bacillus pumilus. Agric. Biol. Chem. 1982, 46, 2659-2665. [CrossRef]

24. Kurasawa, K.; Kuwahara, S.; Enomoto, M. Synthesis of bacilosarcins B and C. Tetrahedron Lett. 2016, 57, 4997-4999. [CrossRef]

25. Azumi, M.; Ogawa, K.I.; Fujita, T.; Takeshita, M.; Yoshida, R.; Furumai, T.; Igarashi, Y. Bacilosarcins A and B, novel bioactive isocoumarins with unusual heterocyclic cores from the marine-derived bacterium Bacillus subtilis. Tetrahedron 2008, 64, 6420-6425. [CrossRef]

26. Wang, H.L.; Li, Z.; Jia, R.N.; Hou, Y.; Yin, J. RecET direct cloning and Redab recombineering of biosynthetic gene clusters, large operons or single genes for heterologous expression. Nat. Protoc. 2016, 11, 1175-1190. [CrossRef] [PubMed]

27. Lin, H.F.; Chen, T.H.; Liu, S.D. The antifungal mechanism of Bacillus subtilis against Pestalotiopsis eugeniae and its development for commercial applications against wax apple infection. Afr. J. Microbiol. Res. 2011, 5, 1723-1728.

28. Wu, L.; Wu, H.; Chen, L.; Xie, S.; Zang, H.; Borriss, R.; Gao, X. Bacilysin from Bacillus amyloliquefaciens FZB42 has specific bactericidal activity against harmful algal bloom species. Appl. Environ. Microbiol. 2014, 80, 7512-7520. [CrossRef] [PubMed]

29. Earl, A.M.; Losick, R.; Kolter, R. Ecology and genomics of Bacillus subtilis. Trends Microbiol. 2008, 16, 269-275. [CrossRef] [PubMed]

30. Terekhov, S.S.; Nazarov, A.S.; Mokrushina, Y.A.; Baranova, M.N.; Potapova, N.A.; Malakhova, M.V.; Elena, N.I.; Ivan, V.S.; Alexander, G.G. Deep functional profiling facilitates the evaluation of the antibacterial potential of the antibiotic amicoumacin. $J$. Antibiot. 2020, 9, 157. [CrossRef]

31. Liu, S.; Han, X.; Jiang, Z.; Wu, G.; Hu, X.; You, X.; Jiang, J.; Zhang, Y.; Sun, C. Hetiamacin B-D, new members of amicoumacin group antibiotics isolated from Bacillus subtilis PJS. J. Antibiot. 2016, 69, 769-772. [CrossRef]

32. Li, Y.; Li, Z.; Yamanaka, K.; Xu, Y.; Zhang, W.; Vlamakis, H.; Kolter, R.; Moore, B.S.; Qian, P.Y. Directed natural product biosynthesis gene cluster capture and expression in the model bacterium Bacillus subtilis. Sci. Rep. 2015, 5, 9383. [CrossRef] [PubMed]

33. Hisayuki, K.; Akira, H.; Natsuko, I.; Yasuhiro, I. Draft genome sequence of marine-derived Bacillus subtilis TP-B0611, a producer of bacilosarcins and amicoumacins. Genome Announc. 2016, 4, e01134-16.

34. Enomoto, M.; Kuwahara, S. Total synthesis of bacilosarcins A and B. Angew. Chem. Int. Edit. 2009, 48, 1144-1148. [CrossRef]

35. Zhang, X.; Zhang, R.Z.; Bao, T.; Rao, Z.M.; Yang, T.W.; Xu, M.J.; Xu, Z.H.; Li, H.Z.; Yang, S.T. The rebalanced pathway significantly enhances acetoin production by disruption of acetoin reductase gene and moderate-expression of a new water-forming NADH oxidase in Bacillus subtilis. Metab. Eng. 2014, 23, 34-41. [CrossRef]

36. Park, H.B.; Perez, C.E.; Perry, E.K.; Crawford, J.M. Activating and attenuating the amicoumacin antibiotics. Molecules 2016, 21, 824. [CrossRef]

37. Blin, K.; Shaw, S.; Steinke, K.; Villebro, R.; Ziemert, N.; Lee, S.Y.; Medema, M.H.; Weber, T. antiSMASH 5.0: Updates to the secondary metabolite genome mining pipeline. Nucleic Acids Res. 2019, 47, W81-W87. [CrossRef] [PubMed]

38. Clinical and Laboratory Standards Institute. Methods for Dilution Antimicrobial Susceptibility Tests for Bacteria that Grow Aerobically; Approved Standards, 9th ed.; Document M07-A9; CLSI: Wayne, PA, USA, 2012.

39. Heine, H.S.; Hershfield, J.; Marchand, C.; Miller, L.; Halasohoris, S.; Purcell, B.K.; Worsham, P.L. In vitro antibiotic susceptibilities of Yersinia pestis determined by broth microdilution following CLSI methods. Antimicrob. Agents Chemother. 2015, 59, 1919-1921. [CrossRef] [PubMed]

40. Clinical and Laboratory Standards Institute. Performance Standards for Antimicrobial Susceptibility Testing; Twenty-Fourth Informational Supplement; Document M100-S24; CLSI: Wayne, PA, USA, 2014. 